\title{
Survival of very preterm infants in the Islamic Republic of Iran: A population-based retrospective cohort study
}

\author{
Forouzan Akrami ${ }^{1}$, Gohar Mohammadi ${ }^{1,2}$, Mehdi Azizmohammad Looha ${ }^{3}$, Abbas Habibelahi ${ }^{4}$, Yadollah Mehrabi ${ }^{5}$, \\ Shahnaz Delbarpoor Ahmadi ${ }^{6}$, Mohammad Heidarzadeh $7,8 *$ (1)
}

Received: 6 Mar 2020

Published: 29 Mar 2021

\section{Abstract}

Background: Estimation of the survival of very preterm infants is necessary to make decisions and design interventions in order to improve their quality of care. This survey aimed to estimate the survival of very preterm infants born at 23 up to 33 weeks of gestational age (GA) in Iran.

Methods: This population-based retrospective cohort study included 8536 infants born before 33 weeks of GA, from March 21st to December 22nd 2013 in Iran. The primary data were extracted from the Iranian national maternal and neonatal registration network (IMAN). All infants who have been discharged alive, followed up by telephone contact up to one year after birth. The Kaplan-Meier and Log-rank tests were performed to estimate survival and to compare survivals, respectively, using SPSS version 26 and R 3.5 .2 softwares.

Results: The overall survival was estimated at $56.70 \%$ (95\% C.I: $55.60 \%-57.80 \%)$ at the end of the follow-up period. Total death rate was estimated at $43.30 \%$ and was significantly decreased with increasing birth weight $(\mathrm{p}<0.0001)$. Survival was increased significantly with increasing GA $(\mathrm{p}<0.0001)$, from $5.7 \%$ at 23 weeks to $79.6 \%$ at 32 weeks. The estimated cumulative proportion of death until the end of the neonatal period had a decreasing trend and then had a steady trend until the end of the follow-up period. The hazard ratio of quadruple or more birth and GA were $1.46(\mathrm{p}=0.021)$ and $0.83(\mathrm{p}<0.001)$, respectively.

Conclusion: The overall estimated survival of very preterm infants was not high. Even with modern perinatal technology and care, early deaths of very preterm infants were still common.

Keywords: Preterm Birth, Survival, Death Rate, Iran

Conflicts of Interest: None declared

Funding: Iranian Society of Neonatology

\section{*This work has been published under CC BY-NC-SA 1.0 license. \\ Copyright $\odot$ Iran University of Medical Sciences}

Cite this article as: Akrami F, Mohammadi G, Azizmohammad Looha M, Habibelahi A, Mehrabi Y, Delbarpoor Ahmadi Sh, Heidarzadeh M. Survival of very preterm infants in the Islamic Republic of Iran: A population-based retrospective cohort study. Med J Islam Repub Iran. 2021 (29 Mar);35:41. https://doi.org/10.47176/mjiri.35.41

\section{Introduction}

The global burden of preterm births is very high world-
Corresponding author: Dr Mohammad Heidarzadeh, heidarzadeh@health.gov.ir

1. Neonatal Health Research Center, Research Institute for Children's Health, Shahid Beheshti University of Medical Sciences, Tehran, Iran

2. Administration and Resources Development affairs, Shahid Beheshti University of Medical Sciences, Tehran, Iran

3. Department of Biostatistics, Faculty of Paramedical Sciences, Shahid Beheshti University of Medical Sciences, Tehran, Iran

4. Neonatal Health Office, Deputy of Public Health, Ministry of Health and Medical Education, Tehran, Iran

5. Department of Epidemiology, School of Public Health and Safety, Shahid Beheshti University of Medical Sciences, Tehran, Iran

6. Deputy of Public Health, Shahid Beheshti University of Medical Sciences, Tehran, Iran

7. Department of Pediatrics, Faculty of Medicine, Tabriz University of Medical Sciences, Tabriz, Iran

8. Deputy of Public Health, Ministry of Health and Medical Education, Tehran, Iran wide. Over the world, for at least a decade, prematurity

$\uparrow$ What is “already known” in this topic:

Advances in the management of perinatal period, including increased use of steroid therapy, mechanical ventilation and treatment with surfactant, have been resulted in increasing the survival of very preterm infants.

\section{$\rightarrow$ What this article adds:}

- The overall survival of very preterm infants was $56.70 \%$ at the end of the one year follow up period.

- Even with modern perinatal technology and care, early deaths of very preterm infants were still common. There is a need for equality in resource distribution based on the perinatal regionalization program. 
has been the leading cause of neonatal morbidity and mortality. It is estimated 15 million newborns are born preterm that accounts for $11 \%$ of births. According to the WHO, the birth between weeks 28-32 is considered as very preterm birth PTB, and the birth between weeks 2228 is considered as extremely PTB. These categories and their differences are clinically significant due to an increase in the rate of mortality and morbidity associated with the reduction in gestational age (GA) at birth $(1,2)$. On the other hand, perinatal management varies in different stages of pregnancy and preterm births are associated with higher costs $(2,3)$.

The high rates of death and loss of potential for the development of under-5 children are major challenges in the developing countries. Approximately two-thirds of deaths occur during the neonatal period due to insufficient access to neonatal intensive care units (NICUs) or inappropriate care (4-6) With rising neonatal survival in the 1990s, the survival of preterm infants has been associated with many severe disabilities. $90 \%$ of babies who are born before 28 weeks survive in HICs, compared with $10 \%$ in LMICs. Low birth weight (BW) and low gestational age (LGA), especially in extremely preterm infants, are associated with the increased disease, death, and subsequent complications such as delay of development, neurological disorders, retinopathy, and visual impairments $(7,8)$.

Integrated interventions have several benefits, including the optimal use of resources, as well as the feasibility of a comprehensive approach to infant-centered care (6). Advances in the management of the perinatal period, including increased use of steroid therapy, mechanical ventilation and treatment with surfactant, and also improvement of quality of care, have been resulted in a significant increase in the survival of LGA infants (9).

It is important to decide whether or not to rescue newborns who are at risk of death or major morbidity ethically. Internationally, there are controversies to decide about resuscitation and early interventions for those infants born before 25 weeks of gestation (10). Estimation of the survival of very and extremely preterm infants is necessary to make decisions and design interventions in order to improve their quality of care. Perinatal interventions in these infants should also be designed to reduce long-term complications (7).

Clinical decisions in preterm births and counseling parents requires the most relevant estimates about outcomes. Although the decision-making process varies from one country to another, a European study on the attitude and practice of physicians suggests that a large group of European neonatologists attending special care in the delivery room or the NICUs suffers some limitations and moral dilemmas (11).

Iranian national maternal and neonatal registration network (IMAN) was launched by the Neonatal Health Office of the Ministry of Health and Medical Education (MOHME) in 2011 to record inpatient birth data. A midwife in each hospital is responsible for entering primary data of the live births, such as sex, GA, BW, Apgar score, resuscitation measures, and neonatal malformations to assess the current situation. The processing of the data helps us to analyze the current situation and design the necessary interventions at the level of each medical university as well as at the national level. Given the high prevalence of preterm birth in Iran (9.2\%) (12) and because of the selective bias of survival data which are usually derived from NICUs, in order to achieve exact estimates for better decisions and interventions, we need population based studies (13). Therefore, this population based survey aimed to estimate the survival of preterm infants born at 23 up to 33 weeks of GA from birth to one year across Iran.

\section{Methods}

This population-based retrospective cohort study included 8536 preterm infants born in less than 33 weeks of gestation, between March $21^{\text {st }} 2013$ and December $22^{\text {nd }}$ 2013 in Iran. Some preterm infants $(n=742)$ were excluded from the study due to incompleteness of information.

After extracting primary data of live births with a $\mathrm{GA}<33$ weeks from the IMAN network, including gestational age, sex, weight, number of newborns, Apgar score, resuscitation measures, and neonatal malformations In order to increase the credibility of the data, the primary data was controlled and completed by the infants' hospital records. In the next step, if the baby had been discharged from the hospital alive, the experts were filling out the follow-up form by telephone contact with the infant's mother. All infants were followed at the age of one year. If it was not possible to make a phone call up to three times, the infant would be excluded from the study. Then primary and follow up data were merged as a dataset and were analyzed.

The pivotal outcome in this study was specified as infants' survival during follow up that was defined as being alive up to infant one year. Gestational age was defined according to an early pregnancy ultrasound scan before 20 weeks of gestation or a certain date of the last menstrual period that has been previously calculated and entered into the IMAN network, based on the instructions. Maternal age, infant's sex, BW, the frequency of pregnancy and multiple births were assessed as the risk factors to update a simple prediction model with a limited number of highly predictive variables.

Descriptive statistics included frequency and percentage were expressed for all factors. The Kaplan-Meier method was used to calculate the survival between different GAs, and a Log-rank test was performed to compare survival. The risk of death was demonstrated with hazard ratios in a $95 \%$ confidence interval. The univariate and multiple Cox regression analysis was used to investigate the effect of variables on infant survival. The stepwise regression analysis was applied in the multiple Cox regression and the multicollinearity problem was completely checked for final selection. The proportional hazard assumption $(\mathrm{PH})$ was tested based on the scaled Schoenfeld residuals for all variables in the Cox regression. The relationship between risk factors was calculated using the chi-square test and linear trend alternative to independence. All analyzes were performed using the IBM SPSS version 26 and R 3.5.2 softwares. A P-value less than 0.05 was considered significant. 


\section{Results}

A total of 7737 preterm infants included in the study, while $4113(53.2 \%)$ were male and 3624 (46.8\%) were female. Among All cases, 43.29\% died (including 44.37\% of males and $42.08 \%$ of females) during the study. Most of the infants $(28.80 \%)$ were born from mothers aged $26-$ 30 years which approximately half of them $(43.30 \%)$ died eventually. 199 births $(2.60 \%)$ belonged to the youngest maternal age group $(<18$ years) and $95(47.74 \%)$ of them died. In mothers over age 3 years, $801(10.40 \%)$ births occurred and $340(42.45 \%)$ cases died. Most of the infants were born from first pregnancy $(49.70 \%)$, and almost half of them died during the follow-up period. Through the six levels of $\mathrm{BW}$, the death rate for $\mathrm{BWs}$ with less than 500 and 500-750 gm was at least 90\%, while in the BWs 1500-2000 gm was $15.52 \%$. Furthermore, there was a significant relation between infant's survival status and $\mathrm{BW}$, as the death rate decreased with increasing BW $(\mathrm{p}<0.001)$. The death rate also declined with increasing GA, significantly $(\mathrm{p}<0.001)$. At the GA of 23 weeks, only $5.7 \%$ of infants survived and the death rate was about $50 \%$ at the GA of 28 weeks (Table 1).

The overall survival was $56.70 \%$ (95\% C.I: $55.60 \%$ $57.80 \%$ ) at the end of the study period. In addition, the estimated cumulative proportion of survival had a downward trend until the end of the neonatal period and then followed a relatively steady trend until the end of the study period (Figs. 1 and 2). The difference in survival between the 28th and 365th days after birth was only 0.044 (Table 2).

The survival was 0.56 (95\% C.I: $0.54-0.57)$ in males and 0.57 (95\% C.I: $0.56-0.60)$ in females at the end of the study period, which were not significantly different (logrank $\mathrm{p}>0.05$ ). The survival was less than $10 \%$ at the $\mathrm{BW}$ group of $500-750 \mathrm{gm}$ and had an upward trend until the rate reached $84 \%$ at the $\mathrm{BW}$ group of $1500-2000 \mathrm{gm}$. The survival of infants born between 23- 28 weeks of GA was less than $50 \%$. Furthermore, the highest survival was ob-

Table 1. Frequency distribution of demographic characteristics of preterm infants and their living status

\begin{tabular}{|c|c|c|c|c|}
\hline \multirow[t]{2}{*}{ Variable } & \multirow[t]{2}{*}{ Total $(\%)$} & \multicolumn{2}{|c|}{ Status } & \multirow[t]{2}{*}{$\mathrm{p}$} \\
\hline & & Alive (\%) & Dead (\%) & \\
\hline \multicolumn{5}{|l|}{ Infant Sex } \\
\hline Male & $4113(53.20)$ & $2288(55.63)$ & $1825(44.37)$ & $0.042^{\mathrm{a}}$ \\
\hline Female & $3624(46.80)$ & $2099(57.92)$ & $1525(42.08)$ & \\
\hline \multicolumn{5}{|c|}{ Maternal Age } \\
\hline$<18$ & $199(2.60)$ & $104(52.26)$ & $95(47.74)$ & $0.292^{\mathrm{b}}$ \\
\hline $19-25$ & $2227(28.80)$ & $1259(56.63)$ & $968(43.47)$ & \\
\hline $26-30$ & $2770(35.80)$ & $1565(56.50)$ & $1205(43.50)$ & \\
\hline $31-35$ & $1740(22.50)$ & $998(57.36)$ & $742(42.64)$ & \\
\hline$>35$ & $801(10.40)$ & $461(57.55)$ & $340(42.45)$ & \\
\hline \multicolumn{5}{|c|}{ Frequency of Pregnancy } \\
\hline 1 & $3848(49.70)$ & $2190(56.91)$ & $1658(43.09)$ & $0.398^{\mathrm{b}}$ \\
\hline 2 & $1725(22.30)$ & $991(57.45)$ & $734(42.55)$ & \\
\hline 3 & $1242(16.10)$ & $695(55.96)$ & $547(44.04)$ & \\
\hline 4 & $544(7.00)$ & $296(54.41)$ & $248(45.59)$ & \\
\hline 5 & $321(4.10)$ & $184(57.32)$ & $137(42.68)$ & \\
\hline 6 & $42(0.50)$ & $23(54.76)$ & $19(45.24)$ & \\
\hline 7 & $11(0.10)$ & $8(72.73)$ & $3(27.27)$ & \\
\hline 8 & $4(0.10)$ & $0(0.00)$ & $4(100.00)$ & \\
\hline \multicolumn{5}{|c|}{ Multiple Births } \\
\hline 1 & $5687(73.50)$ & 3207 (56.39) & $2480(43.61)$ & $0.567^{\mathrm{b}}$ \\
\hline 2 & $1613(20.80)$ & $924(57.28)$ & $689(42.72)$ & \\
\hline 3 & $374(4.80)$ & $231(61.76)$ & $143(38.24)$ & \\
\hline$\geq 4$ & $63(0.80)$ & $25(39.68)$ & $38(60.32)$ & \\
\hline \multicolumn{5}{|c|}{ Birth Weight (g) } \\
\hline$<500$ & $36(0.5)$ & $0(0.0)$ & $36(100.00)$ & \\
\hline $500-750$ & $507(6.6)$ & $50(9.86)$ & $457(90.14)$ & \\
\hline $750-1000$ & $1935(25.0)$ & $594(30.70)$ & $1341(69.30)$ & $<0.0001^{\mathrm{b}}$ \\
\hline $1000-1250$ & $2042(26.4)$ & $1222(59.84)$ & $820(40.16)$ & \\
\hline $1250-1500$ & $2151(27.8)$ & $1666(77.45)$ & $485(22.55)$ & \\
\hline $1500-2000$ & $1005(13.0)$ & $849(84.48)$ & $156(15.52)$ & \\
\hline Missing & $61(0.8)$ & $6(9.83)$ & $55(90.17)$ & \\
\hline \multicolumn{5}{|c|}{ Gestational Age } \\
\hline 23 & $106(1.4)$ & $6(5.7)$ & $100(94.3)$ & $<0.001 b$ \\
\hline 24 & $246(3.2)$ & $30(12.2)$ & $216(87.3)$ & \\
\hline 25 & $388(5.0)$ & $46(11.9)$ & $342(88.1)$ & \\
\hline 26 & $695(8.9)$ & $168(24.2)$ & $527(75.8)$ & \\
\hline 27 & $756(9.7)$ & $286(37.8)$ & $470(62.2)$ & \\
\hline 28 & $1172(15.0)$ & $587(50.1)$ & $585(49.9)$ & \\
\hline 29 & $1193(15.3)$ & $746(62.5)$ & $447(37.5)$ & \\
\hline 30 & 1472 (19.9) & $1122(76.2)$ & $350(23.8)$ & \\
\hline 31 & 1469 (18.8) & $1205(82.0)$ & $264(18.0)$ & \\
\hline 32 & $240(3.1)$ & $191(79.6)$ & $49(20.4)$ & \\
\hline Total & $7737(100.00)$ & $4387(56.70)$ & $3350(43.30)$ & $<0.0001^{\mathrm{c}}$ \\
\hline
\end{tabular}

a: chi-square test of independence; b: linear trend alternative to independence; c: the binomial proportion test 


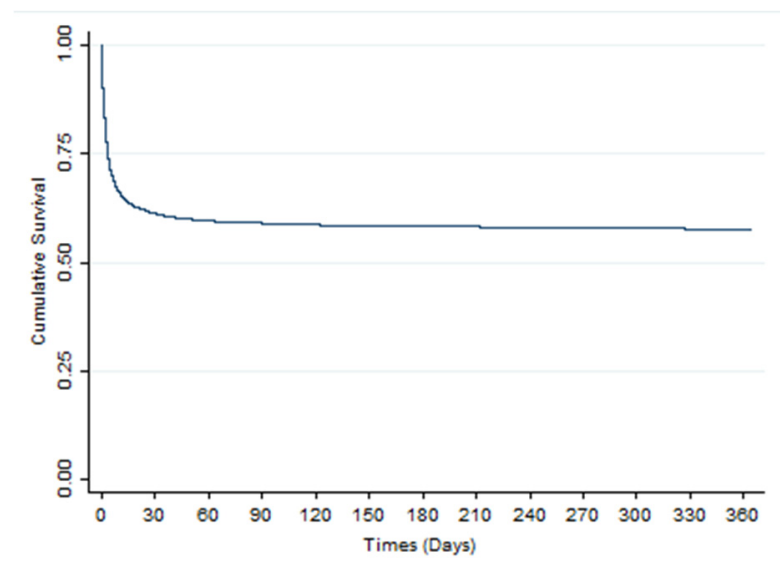

Fig. 1. Survival pattern of preterm infants during follow up period

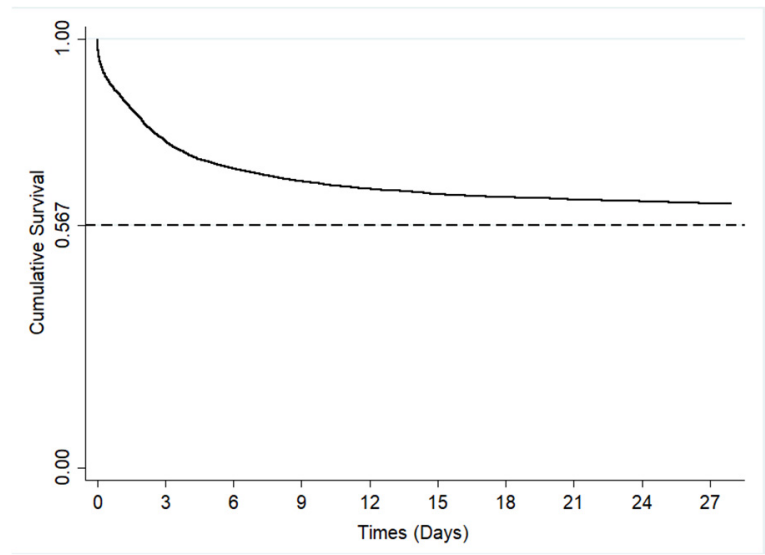

Fig. 2. Survival pattern of premature infants up to 28 days after birth

served at the GA of 32 weeks with a value of $0.80(95 \%$ C.I: 0.75-0.85) (Table 3).

According to the univariate Cox regression results, the $\mathrm{BW}$, multiple births, and GA had significant impacts on the infants' survival. A BW of 1500-2000 gm was considered as the reference group and all other levels were compared with this category. The risk of death in infants weighting less than $500 \mathrm{gm}$ was about 32 times more than the reference group $(p<0.001)$. The hazard ratio declined with increasing BW and the BW group of 1250-1500 gm had a $51 \%$ higher hazard death ratio compared to the BW group of $1500-2000 \mathrm{gm}(\mathrm{p}<0.001)$. Among the multiple births, only the level of quadruple or more births had a significant impact on the hazard ratio compared to the singleton as the reference group. Accordingly, the hazard ratio for quadruple or more births was about $78 \%$ higher than singleton birth $(\mathrm{p}<0.001)$. GA was used as the numeric variable in the cox regression analysis due to violation of $\mathrm{PH}$ assumption in the categorical form. It was showed that per each week increase in GA, death hazard decreased by $31 \%(p<0.001)$. The multiple birth and GA were included in multiple Cox analyses, and the BW was removed due to the multicollinearity problem. According to multiple Cox regression, the HR of quadruple or more births and GA were 1.46 (95\% C.I: $1.06-2.01 ; \mathrm{p}=0.021)$ and 0.83 (95\% C.I: $0.080-0.85 ; \mathrm{p}<0.001)$, respectively (Table 3).
Table 2. Cumulative proportion of Survival pattern at the end of interval times

\begin{tabular}{lccc}
\hline $\begin{array}{l}\text { Interval Times } \\
\text { (days) }\end{array}$ & $\begin{array}{c}\text { Cumulative } \\
\text { proportion of } \\
\text { survival }\end{array}$ & \multicolumn{2}{c}{$95 \%$ Confidence Interval } \\
\cline { 3 - 4 } & 0.863 & & Lower \\
\hline $0-1$ & 0.803 & 0.855 & 0.870 \\
$1-2$ & 0.682 & 0.794 & 0.811 \\
$2-7$ & 0.638 & 0.671 & 0.692 \\
$7-14$ & 0.621 & 0.610 & 0.649 \\
$14-21$ & 0.611 & 0.600 & 0.632 \\
$21-28$ & 0.604 & 0.593 & 0.622 \\
$28-35$ & 0.599 & 0.588 & 0.615 \\
$35-42$ & 0.596 & 0.585 & 0.610 \\
$42-49$ & 0.594 & 0.583 & 0.607 \\
$49-56$ & 0.591 & 0.581 & 0.602 \\
$56-63$ & 0.590 & 0.579 & 0.601 \\
$63-70$ & 0.589 & 0.578 & 0.600 \\
$70-77$ & 0.588 & 0.577 & 0.599 \\
$77-84$ & 0.586 & 0.576 & 0.597 \\
$84-91$ & 0.585 & 0.574 & 0.596 \\
$91-98$ & 0.584 & 0.573 & 0.595 \\
$98-105$ & 0.583 & 0.572 & 0.594 \\
$105-120$ & 0.581 & 0.570 & 0.592 \\
$120-150$ & 0.579 & 0.568 & 0.590 \\
$150-180$ & 0.579 & 0.568 & 0.590 \\
$180-210$ & 0.577 & 0.566 & 0.588 \\
$210-240$ & 0.575 & 0.564 & 0.586 \\
$240-300$ & 0.567 & 0.556 & 0.578 \\
$300-365$ & & &
\end{tabular}

\section{Discussion}

Awareness of the survival of very and extremely preterm infants is necessary to make decisions and design interventions in order to improve their quality of life and prevent long-term complications. Based on the findings, overall survival was estimated at $56.70 \%$ at the end of the follow-up period. As expected, the survival was increased significantly with increasing GA, from $5.7 \%$ at 23 weeks to $79.6 \%$ at 32 weeks; the estimated cumulative proportion of survival had a downward trend until the end of the neonatal period and then followed a relatively steady trend until the end of the study period. The total death rate was estimated at $43.30 \%$ and was significantly decreased with increasing BW. The survival was less than $10 \%$ at the BW group of 500-750 gm and had an upward trend until the rate reached $84 \%$ at the BW group of $1500-2000 \mathrm{gm}$. In a study on 338 infants with BW $\leq 1500$ gm or GA $\leq 32$ weeks who were hospitalized in NICUs of Iran, from October 2013 to March 2014, overall survival based on the point of discharge from the NICU was estimated at $71 \%$ (14). In another study on the survival of 194 newborns with the BW $\leq 1500$ gm and GA $\leq 30$ weeks who had been hospitalized in NICUs of the two referral hospitals in Iran, $75 \%$ of infants survived after 2 days, $50 \%$ after 14 days, and $25 \%$ after 69 days (15). In a population-based audit of inpatient neonatal care based in the East Midlands and Yorkshire regions of England (2013), 2995 white singleton infants were born at 23 to 33 weeks' GA, who survived following admission to a NICU, were included in the study. Overall, $91.9 \%$ of the infants survived to discharge including $91.2 \%$ of male infants and $92.6 \%$ of female infants (16). In a study on the survival of 729 VLBW infants in China (2014), the overall survival of the infants to discharge was $92 \%$ which increased with increasing GA and most of the 


\begin{tabular}{|c|c|c|c|c|c|c|}
\hline \multirow[t]{2}{*}{ Variable } & \multirow{2}{*}{$\begin{array}{l}\text { Proportional } \\
\text { Hazard } \\
\text { p }\end{array}$} & \multirow{2}{*}{$\begin{array}{l}\text { Survival } \\
(95 \% \text { C.I })\end{array}$} & \multicolumn{2}{|c|}{ univariate Analysis } & \multicolumn{2}{|c|}{ Multiple Analysis } \\
\hline & & & $\begin{array}{l}\text { Hazard Ratio } \\
(95 \% \text { C.I })\end{array}$ & $\mathrm{p}$ & $\begin{array}{l}\text { Hazard Ratio } \\
(95 \% \text { C.I })\end{array}$ & $\mathrm{p}$ \\
\hline \multicolumn{7}{|l|}{ Sex of Infants } \\
\hline Male (reference) & 0.19 & $0.56(0.54-0.57)$ & 1 & ---- & 1 & ---- \\
\hline Female & & $0.57(0.56-0.60)$ & $0.94(0.88-1.00)$ & 0.063 & $0.96(0.90-1.03)$ & 0.212 \\
\hline \multicolumn{7}{|l|}{ Maternal Age } \\
\hline $18>($ reference $)$ & 0.32 & $0.52(0.46-0.60)$ & 1 & ---- & ---- & ---- \\
\hline $19-25$ & & $0.56(0.55-0.59)$ & $0.91(0.74-1.13)$ & 0.393 & ---- & ---- \\
\hline $26-30$ & & $0.56(0.55-0.58)$ & $0.91(0.74-1.12)$ & 0.387 & ---- & ---- \\
\hline $31-35$ & & $0.57(0.55-0.60)$ & $0.89(0.72-1.11)$ & 0.303 & ---- & ---- \\
\hline$>35$ & & $0.58(0.54-0.61)$ & $0.89(0.71-1.11)$ & 0.293 & ---- & ---- \\
\hline \multicolumn{7}{|l|}{ Frequency of Pregnancy } \\
\hline 1 (reference) & 0.77 & $0.60(0.55-0.58)$ & 1 & ---- & ---- & ---- \\
\hline 2 & & $0.57(0.55-0.60)$ & $0.99(0.91-1.08)$ & 0.737 & ---- & ---- \\
\hline 3 & & $0.56(0.53-0.59)$ & $1.04(0.94-1.14)$ & 0.455 & ---- & ---- \\
\hline$>4$ & & $0.55(0.52-0.59)$ & $1.05(0.94-1.17)$ & 0.371 & ---- & ---- \\
\hline Birth Weight (g) & & $* *$ & & & & \\
\hline$<500$ & 0.06 & $0.00(0.00-0.00)$ & $32.25(25.86-53.66)$ & $<0.001$ & ---- & ---- \\
\hline $500-750$ & & $0.09(0.08-0.13)$ & $14.19(11.82-17.03)$ & $<0.001$ & ---- & ---- \\
\hline $750-1000$ & & $0.31(0.29-0.33)$ & $6.85(5.80-8.09)$ & $<0.001$ & ---- & ---- \\
\hline $1000-1250$ & & $0.60(0.59-0.62)$ & $3.00(2.53-3.56)$ & $<0.001$ & ---- & ---- \\
\hline $1250-1500$ & & $0.78(0.76-0.79)$ & $1.51(1.26-1.81)$ & $<0.001$ & ---- & ---- \\
\hline 1500-2000 (reference) & & $0.84(0.82-0.87)$ & 1 & ---- & ---- & ---- \\
\hline Multiple Births & & $* *$ & & & & \\
\hline 1 (reference) & 0.21 & $0.56(0.55-0.58)$ & 1 & ---- & 1 & ---- \\
\hline 2 & & $0.57(0.55-0.60)$ & $0.98(0.90-1.06)$ & 0.594 & $0.97(0.0 .89-1.06)$ & 0.507 \\
\hline 3 & & $0.62(0.57-0.69)$ & $0.85(0.72-1.00)$ & 0.055 & $0.85(0.72-1.01)$ & 0.066 \\
\hline$>4$ & & $0.40(0.29-0.54)$ & $1.78(1.29-2.46)$ & $<0.001$ & $1.46(1.06-2.01)$ & 0.021 \\
\hline Gestational Age & & $* *$ & & & & \\
\hline 23 & 0.24 & $0.06(0.03-0.12)$ & $0.69(0.68-0.70)$ & $<0.001$ & $0.83(0.80-0.85)$ & $<0.001$ \\
\hline 24 & & $0.12(0.09-0.17)$ & & & & \\
\hline 25 & & $0.12(0.09-0.16)$ & & & & \\
\hline 26 & & $0.24(0.21-0.28)$ & & & & \\
\hline 27 & & $0.38(0.35-0.41)$ & & & & \\
\hline 28 & & $0.50(0.47-0.53)$ & & & & \\
\hline 29 & & $0.63(0.60-0.65)$ & & & & \\
\hline 30 & & $0.76(0.74-0.78)$ & & & & \\
\hline 31 & & $0.82(0.80-0.84)$ & & & & \\
\hline 32 & & $0.80(0.75-0.85)$ & & & & \\
\hline
\end{tabular}

deaths occurred within the neonatal period. The mortality rate of VLBW and ELBW infants was $11 \%$ and $27 \%$, respectively, which was higher than that in infants with a BW $\geq 1500$ gm (17). Shim et al. (2015) in their study on the survival of 2,386 VLBW infants in Korea also, reported decreasing mortality rates with increasing BW and GA. The survival of Korean VLBW and ELBW infants based on the point of discharge from the NICU was $84.8 \%$ and $69.6 \%$, respectively. Comparison of the results of the present study with the results of similar studies shows the similarity of the trend of survival in preterm infants. Despite our study, in most studies, survival has been calculated from the time of admission in NICUs and therefore was more. Higher survival in similar studies can also be related to the smaller sample size and short follow up period.

The survival were not significantly different between male and female infants at the end of the study period. According to multiple Cox regression, the hazard ratio of quadruple or more birth and GA were 1.46 and 0.83 , respectively. This means that the risk of death is reduced by $17 \%$ per week increasing in GA, and for births of 4 or more, the risk of death increases by $46 \%$, comparing with single births. In a multicenter study of preterm infants, survival improved especially at 30 weeks of GA, and female and single infants survived more than males and multiples (18). A Canadian multicenter study also reported better survival of female infants (19). Multiple pregnancies are associated with a greater risk of preterm birth and therefore higher rate of infant death. Based on results of the Demographic and Health Survey (DHS, 19902000), the risk of death in multiple births was about six times higher than single birth in the neonatal period in developing countries (20). Thus, it seems for those infants born after 25 weeks, the decision for early interventions should be mainly made based on infants' GA, BW, and the number of neonates born in each pregnancy regarding the level of regional perinatal care services, which is close to results of similar studies (10). Implementation of the perinatal regionalization program has been shown to improve utilization of resources and neonatal outcomes (21). Although several guidelines have been adopted and implemented to provide standard care, national studies have shown the need for better care to improve outcomes of preterm infants $(22,23)$.

As with any retrospective study, this point can be con- 
sidered as a limitation because of missing information. Given the need for enough time to complete the data by all universities, the analysis of the first data set was done with delay. But despite other studies, estimation of survival after one year follow up period from birth than from hospitalization in NICUs to discharge time is the strength point of our study. The results can also be considered as baseline survival to compare and determine the variations in further years.

\section{Conclusion}

The estimated total survival of very preterm infants shows that even with modern perinatal technology and care, early deaths of very and extremely preterm infants were still common across the country. The findings can help us for ethical decision- making to withhold or withdraw the care of very and extremely preterm infants at the time of birth and after it based on available resources and survival in different areas. Regionalization of perinatal care and decision-making based on survival and influencing factors, especially in provinces with high percentages of preterm infants born outside of level III centers, is recommended to improve survival and perinatal outcomes.

\section{Acknowledgments}

This study was supported technically and financially by the Iranian Society of Neonatology. The authors appreciate all university expert staff who contributed to data collection.

\section{Ethical considerations}

The study was approved by the Institutional Review Board and Research Ethics Committee of the Neonatal Health Research Center, and Research Ethics Committee of Shahid Beheshti University of Medical Sciences (IR.SBMU.RAM.REC.1394.156), Tehran, Iran.

\section{Conflict of Interests}

The authors declare that they have no competing interests.

\section{References}

1. Blencowe H, Cousens S, Oestergaard MZ, Chou D, Moller A-B, Narwal R, et al. National, regional, and worldwide estimates of preterm birth rates in the year 2010 with time trends since 1990 for selected countries: a systematic analysis and implications. Lancet. 2012;379(9832):2162-72.

2. World Health Organization. Born too soon: the global action report on preterm birth. 2012; Available from: http://www.who.int/pmnch/media/news/2012/201204_borntoosoonrep ort.pdf

3. World Health Organization. Newborns: reducing mortality. 2012; Available from: http://www.who.int/mediacentre/factsheets/fs333/en/.

4. Jacob J, Kamitsuka M, Clark RH, Kelleher AS, Spitzer AR. Etiologies of NICU deaths. Pediatrics. 2015;135(1):e59-e65.

5. Barfield W, D’Angelo D, Moon R, Lu M, Wong B, Iskander J. CDC grand rounds: public health approaches to reducing US infant mortality. Morb Mortal Weekly Rep. 2013;62(31):625.

6. Jensen SK, Bouhouch RR, Walson JL, Daelmans B, Bahl R, Darmstadt GL, et al., editors. Enhancing the child survival agenda to promote, protect, and support early child development. Semin Perinatol; 2015. Elsevier.

7. Doyle LW, Saigal S. Long-term outcomes of very preterm or tiny infants. NeoReviews. 2009;10(3):e130-e7.
8. Emsley H, Wardle S, Sims D, Chiswick M, d'Souza S. Increased survival and deteriorating developmental outcome in 23 to 25 week old gestation infants, 1990-4 compared with 1984-9. Arch Dis Child Fetal Neonatal Ed. 1998;78(2):F99-F104.

9. Hack M, Fanaroff AA. Outcomes of children of extremely low birthweight and gestational age in the 1990's. Early Hum Dev. 1999;53(3):193-218.

10. Pignotti M, Donzelli G. Perinatal care at the threshold of viability: an international comparison of practical guidelines for the treatment of extremely preterm births. Pediatrics. 2008;121(1):e193-8.

11. Cuttini M, Nadai M, Kaminski M, Hansen G, de Leeuw R, Lenoir S, et al. End-of-life decisions in neonatal intensive care: physicians' selfreported practices in seven European countries. Lancet. 2000;355(9221):2112-8.

12. Vakilian K, Ranjbaran M, Khorsandi M, Sharafkhani N, Khodadost M. Prevalence of preterm labor in Iran: A systematic review and metaanalysis. Int J Reprod Biomed. 2015;13(12):743.

13. Evans D, Levene M. Evidence of selection bias in preterm survival studies: a systematic review. Arch Dis Child Fetal Neonatal Ed. 2001;84(2):F79-F84.

14. Ghorbani F, Heidarzadeh M, Dastgiri S, Ghazi M, Rahkar Farshi M. Survival of Premature and Low Birth Weight Infants: A Multicenter, Prospective, Cohort Study in Iran. Iran J Neonatal. 2017;8(1):16-22.

15. Navaei F, Aliabady B, Moghtaderi J, Moghtaderi M, Kelishadi R. Early outcome of preterm infants with birth weight of $1500 \mathrm{~g}$ or less and gestational age of 30 weeks or less in Isfahan city, Iran. World J Pediatr. 2010;6(3):228-32.

16. Shrestha S, Dangol SS, Shrestha M, Shrestha R. Outcome of preterm babies and associated risk factors in a hospital. J Nepal Med Assoc. 2010;50(180).

17. Zhou WQ, Mei YB, Zhang XY, Li QP, Kong XY, Feng ZC. Neonatal outcomes of very preterm infants from a neonatal intensive care center. World J Pediatr. 2014;10(1):53-8.

18. Copper RL, Goldenberg RL, Creasy RK, DuBard MB, Davis RO, Entman SS, et al. A multicenter study of preterm birth weight and gestational age - specific neonatal mortality. Am J Obstet Gynecol. 1993;168(1):78-84.

19. Effer SB, Moutquin JM, Farine D, Saigal S, Nimrod C, Kelly E, et al. Neonatal survival rates in 860 singleton live births at 24 and 25 weeks gestational age. A Canadian multicentre study. BJOG. 2002;109(7):740-5.

20. Mahy M. Childhood Mortality in the Developing World: A Review of Evidence from the Demographic and Health Surveys, DHS Comparative Reports No. 4. Calverton, MD: ORC Macro. 2003.

21. Lasswell SM, Barfield WD, Rochat RW, Blackmon L. Perinatal regionalization for very low-birth-weight and very preterm infants: a meta-analysis. JAMA. 2010;304(9):992-1000.

22. Eskandari Z, Akrami F, Razvi Nejad M, Almasi-Hashiani A, Heidarzadeh M. Assessing Family-Centered Care in Iranian NICUs from Perspective of Neonatal Individual Developmental Care. Iran J Neonatol 2020;11(4):87-92.

23. Mohagheghi P, Vakilian R, Sabet SA, Heidarzadeh M, Akrami F, Habibelahi A, et al. Impelementation of kangaroo mother care. Int $\mathrm{J}$ Life Sci Pharma Res. 2017;7(2):L1-L8. 